\title{
Antidiarrhoeal activity of Arque-Ajeeb, a compound formulation of Unani medicine in rats
}

\author{
M Aleem Khan ${ }^{1}$, Naeem A Khan ${ }^{1}$, Iqbal A Qasmi ${ }^{1}$, Ghufran Ahmad ${ }^{1}$ and Shadab Zafar ${ }^{2}$ ** \\ 'Department of Ilmul Advia (Pharmacology), Faculty of Unani Medicine, Aligarh Muslim University, Aligarh- \\ 202002, Uttar Pradesh, India, ${ }^{2}$ Medical Officer-in-Charge, Unani Dispensary, Municipal Corporation of Delhi, \\ Jhatikra, New Delhi-110043, India
}

\begin{abstract}
SUMMARY
The efficacy of Arque-Ajeeb (AA), a compound formulation of Unani medicine was investigated for antidiarrhoeal activity against barium sulphate-induced gut motility and castor oil-induced diarrhoea in rats. The control, standard and test groups of experimental animals were administered with distilled water (p.o.), lomotil (p.o.) and $A A(0.007 \mathrm{ml}$ and $0.014 \mathrm{ml} / 100 \mathrm{~g}$, p.o.) respectively. Barium sulphate and castor oil were administered after 15 and $60 \mathrm{~min}$ respectively in each group of first and second experiment. The distance traveled by barium sulphate in small intestine was measured after 15 and $30 \mathrm{~min}$ of barium sulphate administration and diarrhoea was observed every 30-min for six hour after castor oil administration. Oral administration of $A A$ caused significant reduction in diarrhoea. $A A$ may have the potential to reduce the diarrhoea in rats.
\end{abstract}

Key words: Arque-Ajeeb; Gut motility; Diarrhoea; Rats

\section{INTRODUCTION}

Diarrhoea is a major health problem especially for children under the age of 5 year and up to $17 \%$ of all death in the indoor pediatrics patient is related to diarrhoea. Worldwide distribution of diarrhoea account for more then 5-8 million deaths each year in infants and small children less than 5 year especially in developing countries (Fauci et al., 1998). According to WHO estimation for the year 1998, there were about 7.1 million deaths due to diarrhoea (Park, 2000).

Arque-Ajeeb (Arque-e-Hayat, Zam Zam, Qulzum, Akseer-e-Azam) is a compound formulation of Unani medicine containing Satt-e-Podina (plants extract of Mentha arvensis Linn), Satt-e-Ajwain (seeds extract of Trachyspermum ammi Linn) and Kaphoor (Camphor) (Khan, 1985). It is reputed for their beneficial effects in treatment of diarrhoea

*Correspondence: Dr Shadab Zafar, Medical Officer Incharge, Unani Dispensary, Municipal Corporation of Delhi, Jhatikra, New Delhi-110043, India. E-mail: shadab_zafar@rediffmail.com
(Khan, 1995) and cholera (Gilani, 1938), but the claim of the efficacy is yet to be tested. The drug is said to possess antispasmodic, digestive (Qarshi, 1985) and antiflatulence (Anon, 1993) properties. Therefore the present study has been planned to investigate the real efficacy of $A A$ in rats. The goal of this study is to find effective dose of $A A$ and its ameliorating potential in diarrhoea as a supporting evidence of its antidiarrhoeal property.

\section{MATERIALS AND METHODS}

\section{Drugs}

Satt-e-Podina, Satt-e-Ajwain and Kaphoor were procured from Dawakhana Tibbia College, Aligarh Muslim University, Aligarh, India. Barium Sulphate (E. Merck India Ltd.), castor oil (Pragati Enterprises Ltd., India), carboxymethyle cellulose (CMC) (CDH Ltd., India), lomotil (Diphenoxylate $2.5 \mathrm{mg}+$ Atropin sulphate $0.025 \mathrm{mg}$ ) (Searle India Ltd.) were procured from the respective source. The solution of lomotil was prepared in distilled water, while the $15 \%$ solution of barium 
sulphate was prepared in $0.5 \%$ carboxymethyle cellulose.

\section{Preparation of Arque-Ajeeb (AA)}

All the three constituents viz: Satt-e-Podina, Satt-eAjwain and Kaphoor of solid form were mixed in equal (1:1:1) ratio. After mixing it turns into liquid form which is known as Arque-Ajeeb. It was diluted with distilled water before administration.

\section{Animals}

Albino rats (150-200 g) of either sex were procured from Laboaid animal house, Meerut, India. The animals were divided in-groups of 6 each and housed under standard laboratory conditions with food and water provided ad libitum. The experiments were performed between 09:00 and 17:00 hrs. The animal ethics committee of Aligarh Muslim University approved the study protocol.

\section{Barium sulphate induced gut motility}

The experiment includes four groups (pre-treatment/ post-treatment): (I) Control (distilled water, $2 \mathrm{ml} /$ rats)/barium sulphate $(10 \mathrm{ml} / \mathrm{kg})$; (II) standard (lomotil, $0.7 \mathrm{mg} / 100 \mathrm{~g}) /$ barium sulphate $(10 \mathrm{ml} /$ kg); (III) $A A(0.007 \mathrm{ml} / 100 \mathrm{~g}) /$ barium sulphate (10 $\mathrm{ml} / \mathrm{kg})$ and (IV) $A A(0.014 \mathrm{ml} / 100 \mathrm{~g}) /$ barium sulphate $(10 \mathrm{ml} / \mathrm{kg})$. All the doses of control, standard and $A A$ were administered orally in nonfasted animals and after 15 min barium sulphate solution was administered by the same route in each group.

All the animals of each group were divided into two subgroups. Half animals of each group were sacrificed after $15 \mathrm{~min}$ and another half animals were sacrificed after $30 \mathrm{~min}$ of barium sulphate administration. Small intestine of each animal were removed surgically and the distance traveled by barium sulphate was measured and expressed as a percentage of the total length of small intestine (from pylorus to the ileocoecal junction).

\section{Caster oil induced diarrhoea}

The experiment includes four groups (pre-treatment/ post-treatment): (I) Control (distilled water, $2 \mathrm{ml} /$ rats)/caster oil (1 ml/rat); (II) standard (lomotil, 0.7 $\mathrm{mg} / 100 \mathrm{~g}) /$ caster oil $(1 \mathrm{ml} / \mathrm{rat}) ;$ (III) $A A(0.007$ $\mathrm{ml} / 100 \mathrm{~g}) /$ caster oil $(1 \mathrm{ml} / \mathrm{rat})$ and (IV) $A A(0.014$ $\mathrm{ml} / 100 \mathrm{~g}) /$ caster oil $(1 \mathrm{ml} / \mathrm{rat})$. All the doses of control, standard and $A A$ were administered orally in non-fasted animals and after $60 \mathrm{~min}$ caster oil was administered by the same route in each group.

All animals were screened initially by giving $1.0 \mathrm{ml}$ of castor oil orally and only those animal showing diarrhoea were selected for the main study. After the administration of caster oil each animal were kept in a separate cage and examined every $30 \mathrm{~min}$ for the presence of diarrhoea up to $6 \mathrm{hr}$.

Diarrhoea was defined as the presence of fluid in the stool, which stained the absorbent paper placed beneath the cage. The total number of respondents and the number of stools passed during the $6 \mathrm{hrs}$ period were recorded for each rat. The purging index (PI) was calculated by the following formula:

$\mathrm{PI}=\frac{\% \text { respondents } \mathrm{X} \text { average number of stool }}{\text { Average latent period }}$

\section{Statistical analysis}

All the values were expressed as mean \pm S.E.M. Students t-test was used to analyze significance of the two means. Probability level of less than 5\% was considered as statistically significant.

\section{RESULTS}

In the animals of standard group the total length traveled by barium sulphate was found highly significant $(P<0.001)$ at $15 \mathrm{~min}$ and moderately significant $(P<0.01)$ at $30 \mathrm{~min}$ as compared to control value. Similarly the effect of 0.007 and $0.014 \mathrm{ml} / 100 \mathrm{~g}$ doses of $A A$ were found highly significant $(P<0.001)$ at $15 \mathrm{~min}$ and moderately significant $(P<0.01)$ at $30 \mathrm{~min}$ interval as compared to control value. The results of the study are shown in Table 1.

The study shows that standard and 0.007 and $0.014 \mathrm{ml} / 100 \mathrm{~g}$ doses of $A A$ markedly reduces the number of respondents from $100 \%$ to $16.67 \%$, $33.33 \%$ and $33.33 \%$ respectively. The mean latent period of standard animals was found highly significant $(P<0.001)$ and both doses of $A A$ were found moderately significant $(P<0.01)$ as compared to control value. The average number of stools of standard and both doses of $A A$ were found nonsignificant $(P>0.05)$. However the standard and both doses of $A A$ resulted a very low purging index. The results of the study are shown in Table 2 . 
Table 1. Effect of $A A$ on barium sulphate induced gut motility

\begin{tabular}{clccc}
\hline \multirow{2}{*}{ Gp. } & Dose & $\mathrm{n}$ & \multicolumn{2}{c}{ Length traveled by barium sulphate in cm (Mean \pm S.E.M.) } \\
\cline { 4 - 5 } & & & After $15 \mathrm{~min}$ & After $30 \mathrm{~min}$ \\
\hline I & $2 \mathrm{ml} / \mathrm{rat}$ & 6 & $55.45 \pm 5.06$ & $72.97 \pm 11.21$ \\
II & $0.7 \mathrm{mg} / 100 \mathrm{gm}$ & 6 & $0.0^{* * *}$ & $1.52 \pm 1.01^{* *}$ \\
III & $0.007 \mathrm{ml} / 100 \mathrm{gm}$ & 6 & $9.18 \pm 1.06^{* * *}$ & $12.61 \pm 4.03^{* *}$ \\
IV & $0.014 \mathrm{ml} / 100 \mathrm{gm}$ & 6 & $2.42 \pm 0.73^{* * *}$ & $4.42 \pm 1.42^{* *}$ \\
\hline
\end{tabular}

${ }_{* * P}<0.01$ and ${ }^{* * *} P<0.001$ statistically significant as compared to control value.

$\mathrm{n}$, number of animals in each group.

Table 2. Effect of $A A$ on castor oil induced diarrhoea

\begin{tabular}{clccccr}
\hline Gp. & Dose & n & \% respondent & $\begin{array}{c}\text { Mean latent period in } \\
\text { hour } \pm \text { S.E.M. }\end{array}$ & $\begin{array}{c}\text { Mean number of } \\
\text { stools } \pm \text { S.E.M. }\end{array}$ & $\begin{array}{c}\text { Purging index } \\
(\text { PI })\end{array}$ \\
\hline I & $2 \mathrm{ml} / \mathrm{rat}$ & 6 & 100 & $1.16 \pm 0.07$ & $0.16 \pm 1.52$ & 185.69 \\
II & $0.7 \mathrm{mg} / 100 \mathrm{gm}$ & 6 & 16.67 & $5.83 \pm 0.15^{* * *}$ & $0.33 \pm 0.30^{\mathrm{NS}}$ & 0.95 \\
III & $0.007 \mathrm{ml} / 100 \mathrm{gm}$ & 6 & 33.33 & $4.83 \pm 0.67^{* *}$ & $0.33 \pm 0.19^{\mathrm{NS}}$ & 2.29 \\
IV & $0.014 \mathrm{ml} / 100 \mathrm{gm}$ & 6 & 33.33 & $5.00 \pm 0.57^{* *}$ & $0.33 \pm 0.19^{\mathrm{NS}}$ & 2.22 \\
\hline
\end{tabular}

${ }^{* *} P<0.01$ and ${ }^{* * *} P<0.001$ statistically significant as compared to control value and ${ }^{\mathrm{NS}} P>0.05$ (non-significant). $\mathrm{n}$, number of animals in each group.

\section{DISCUSSION}

The gastrointestinal tract is innervated by both the parasympathetic and sympathetic fibers of the autonomic nervous system. The peristaltic movement of gastrointestinal tract is myogenic in character and is mainly initiated by the local reflexes and can occur without neural connections to the brain or the spinal cord. The extrinsic nerves to the intestine appear to have only a minor role in modulating the peristaltic activity of the organ (Pierce et al., 1971). Earlier study on barium sulphate show that barium sulphate is a classic osmotic type of purgative (Chatterjee, 1993). Thus gut motility test with barium sulphate was carried out to find the effect of $A A$ on peristaltic movement.

Castor oil, which was use as a purgative in the present study, is degraded by lipase into glycerin and ricinoleic acid. It is known that ricinoleic acid is not absorbed and stimulates secretion from the mucosa of the small intestine leading to diarrhoea. Regarding the mechanism of diarrhoea induced by castor oil, it has been suggested that stimulation of the intestinal mucosa by castor oil enhance prostaglandins and platelet activating factor production, which cause inflammation of the intestinal mucosa leading to enhance intestinal motility and secretion responsible for diarrhoea (Kase et al., 1996). In view of the above discussion our findings suggest that $A A$ reduces the gut motility and may suppress the above inflammatory parameters thus reduces the secretary components of the gut.

\section{CONCLUSION}

All the result taken together show that aqueous extract of $A A$ contains pharmacologically active substance with antidiarrhoeal properties. Thus we presume that $A A$ can be developed for the treatment of diarrhoea. However, more detailed phytochemical studies are necessary to identify the active principle and exact mechanism of action.

\section{ACKNOWLEDGMENTS}

The authors are thankful to the authority of the institution for providing all kind of help needed.

\section{REFERENCES}

Anonymous. (1993) National Formulary of Unani Medicine, Vol. I, pp. 318, Ministry of Health and Family Welfare, New Delhi, India.

Chatterjee TK. (1993) Handbook on Laboratory Mice and Rats, pp. 157, Jadavpur University Press, Jadavpur, India. 
Fauci AS, Bravnwold E, Isselpacher K, Wilson JD, Martin JB, Kasper DL, Hauser SL and Longo DL. (1998) Harrisons Principles of Internal Medicine, Vol. I, pp. 236-242, McGraw Hill Company, New York.

Gilani, GI. (1938) Makhzanul Murakkabat Wa Mouallime-Dawa Sazi, pp. 250, Kutub Khana Anjuman Taraqqi Urdu, Jama Masjid, Delhi, India.

Kase Y, Hayakawa T, Takeda S, Ishige A, Aburada M, Okada M. (1996) Pharmacological studies on antidiarrhoeal effects of Hange-Shashin-To. Biol. Pharm. Bull. 19, 1367-1370.

Khan A. (1995) Bayaz-e-Ajmal, pp. 231, Aijaz Publishing House, Delhi, India.
Khan AG. (1985) Maseehul Mulk Ke Murakkabat, Vol. II, pp. 196, Urdu Dawakhana, Gurgaon, Haryana, India.

Park K. (2000) Parks Textbook of Preventive and Social Medicine, pp. 172-175, M/S Banarsidas Bharat Publishers, Jabalpur, India.

Pierce NF, Carpenter CCI, Elliot HI, Greenough WB. (1971) Effect of prostaglandins, theophylline and cholera exotoxin upon transmucosal water and electrolyte movement in canine jejunum. Gastroenterol. 60, 22-32.

Qarshi MH. (1985) Tibbi Pharmacopia, Vol. I, pp. 330, Kareemi Press, Lahore, Pakistan. 